\title{
Reframing Web Accessibility in Post-Secondary Education: Examining the Role of the Educator in the Curation and Creation of Accessible Digital Course Content
}

Kim Ashbourne

Faculty of Education

University of Victoria

\section{Correspondence:}

Kim Ashbourne

kashbourne [at] uvic.ca

\begin{abstract}
Web accessibility is emerging as a key issue and opportunity for educators in postsecondary institutions (Brown, 2018; Gronseth, 2018). Many factors affect web accessibility, yet little literature examines web accessibility factors relative to literacy, pedagogy, course culture, course content curation and information design for learningareas that rest firmly within an educator's domain. What facets are specifically relevant to post-secondary educators? The conference presentation, this proceeding, and a subsequent article for the OTESSA journal that addresses the broader construct of digital accessibility, invite critical engagement with web accessibility practices, accessible course content, and the digital accessibility of technology-mediated learning environments. Together and individually, they offer educators various points of entry that are relevant to praxis and seek to ignite discussions and interventions that build educators' agency and self-efficacy to co-create accessible courses with students with (and without) disabilities.

Keywords: digital accessibility, web accessibility, disability, ableism, postsecondary praxis, accessible course content, technology-mediated learning environments
\end{abstract}




\section{Introduction}

Web accessibility is emerging as a key issue and opportunity for educators in post-secondary education institutions who are using the internet to address a wide range of learner needs (Brown, 2018; Gronseth, 2018). Web accessibility efforts in post-secondary education are broadly concerned with removing barriers experienced by prospective students, students, alumni, faculty, and staff and the broader academic and professional communities with whom they engage who experience physical, cognitive, socioeconomic, and/or geopolitical barriers to professional or educational engagement with the institution, each other, or both via the internet (Lorca et al., 2018).

One of the most pressing web accessibility issues in post-secondary education is the ongoing production and dissemination of digitally inaccessible course content (Silberman, 2018). This practice places students with disabilities at an educational disadvantage and puts institutions at risk of litigation. The fact that universities from Harvard to MIT have been sued over inaccessible online course content is evidence of the very real financial consequences of noncompliance for institutions (Kimmons, 2017; Lewin, 2015) and the equally real personal consequences for people who are left out and held in the margins. Post-secondary institutions often make significant efforts in the areas of policy, accessibility support services, and accessibility-informed procurement practices, but until educators and students learn and consistently apply the skills necessary to identify and create accessible digital content, inaccessible course content will continue to be a problem.

\section{Locating the Educator's Role in Web Accessibility}

Locating the educator's role and efficacy in web accessibility is a challenge. What makes course content inaccessible? Numerous factors affect web accessibility in post-secondary education, many of which are tangential at best to the workflow and work product of educators and their learners. It could be reasonably argued that web accessibility factors stemming from technology procurement, staff training and support, administrative processes and policies, and audit or oversight voids would be in the institution's domain to address. Causes relative to technology design, system integration, or proprietary tech support would be the responsibility of third-party vendors. Considerations related to archives, collections, copyright and publication are typically the domain of libraries and publishers. This ocean of factors is generally well-supported by an ever-growing body of technical and/or policy research and guidelines (American Institutes for Research \& Center on Technology and Disability, 2016; Coughlan \& Lister, 2018; Rogers et al., 2009; US Department of Education \& Office of Educational Technology, 2017; Waldors Verne, 2019; Wood et al., 2017). Also, much of the web accessibility rhetoric in post-secondary education relates to legislative shifts, legal precedents, marketing, corporate social responsibility, and the creation and maintenance of university websites (Bradbard \& Peters, 2008; Lorca et al., 2018). Understandably, educators may not see much relevance to their practice in these discussions.

How might we define reasonable boundaries for educators' area of influence within web accessibility in post-secondary education? Whether educators are teaching face-to-face, blended, or online courses, wherever and whenever educators and students use digital technologies and the internet to share knowledge, there is an opportunity for educators to engage with the accessibility of the content they curate and create for, and with, learners. Though not an explicit element of curriculum, educators model digital workflows throughout their academic career. It is incumbent on educators to regard themselves and their students not as 
passive recipients of content, but as active creators (O'Byrne, 2014) who need skills to participate in an accessible digital world. In my session, and in the OTESSA journal article to follow, I refer to these skills as Accessible Digital Content Literacy Skills.

Now, I want to be very careful not to appear reductionist. For educators to see a more fulsome picture of how web accessibility is relevant to praxis, the field of education needs to more deeply engage with accessibility discourse relative to pedagogy and pedagogic culture toward accessibility (Gay et al., 2017, Dolmage, 2017). That said, as one of many possible points of entry, I feel we need to grapple with what I perceive to be a pervasive, unexplored literacy gap.

\section{The Need for Accessible Digital Content Literacy Skills}

Given the breadth of research on the technical and policy factors, web accessibility could appear to be a technical (e.g., code, design or systems integration) and/or a policy issue to resolve. However, there are text-based, authoring, and content curation issues that block accessibility. Accessible digital content literacy skills are skills specifically related to reading, identifying, curating, and writing/creating web accessible digital content. These skills are commonly itemized in web accessibility technology and compliance literature as content skills, not literacy skills, as evidenced in the Web Content Accessibility Guidelines (WCAG) (Caldwell et al., 2010). Research out of the computer sciences and business fields not only acknowledges the need for these specific skills but also investigates overlaps between various writing strategies recommended in WCAG and writing strategies employed for search engine optimization (Lippay, 2016; Moreno \& Martinez, 2013). Unfortunately, these skills are often missing from web literacy discourse, which is concerned with online reading, writing, participation, and collaboration skills (Chung et al., n.d.; O'Byrne, 2014), and digital literacy discourse, which is concerned with skills needed to produce and engage with digital content, regardless of its distribution medium (Hobbs, 2017).

Education often seems to cede discourse related to web accessibility barriers and the skills needed to remove them to fields such as computer science, and to institutional agents such as student accessibility offices and marketing departments (Bradbard \& Peters, 2010; Lewthwaite \& Sloan, 2016). Claiming specific aspects of web accessibility as pedagogical and/or literacyrelated represents a significant opportunity for educators to better define their role in addressing web accessibility issues in post-secondary education and foster more accessible digital knowledge sharing communities beyond the institution.

\section{Recommendations for Future Research}

Educators and learners must engage with, normalize, and model accessible digital content literacy skills to co-create accessible course content and proactively contribute to wider efforts to make the web an increasingly accessible space for all. In doing so, educators extend the educative value of the course content far beyond the classroom.

The field of education needs to critically re-examine web accessibility from within the educator's domain, using frameworks from the field of education. Drawing from web accessibility, literacy, learning theory and pedagogical literature, more research is needed to identify interventions that might satisfy the following four criteria: (a) respect the lived-experiences of learners and educators with disabilities; (b) pedagogically support learning and inclusion; (c) technically comply with WCAG; and (d) are typically within educators' control. This reframing would have implications for course culture, course content curation, online collaboration and co-creation 
practices, information design for learning, archive, search, digital knowledge sharing, and other digital accessibility considerations in education. Finally, more discourse is needed around educators' agency and self-efficacy (Sanderson et al., 2018) to develop and model accessible digital content literacy skills and inclusion practices in technology-integrated learning environments.

\section{Author's Contributions}

Kim Ashbourne conducted the literature review and was the sole contributing author.

\section{Open Researcher and Contributor Identifier (ORCID)}

Kim Ashbourne (iD https://orcid.org/0000-0002-3527-1973

\section{Acknowledgements}

The author respectfully acknowledges the feedback provided by Dr. Valerie Irvine, Dr. Michael Paskevicius, and Dr. Graham McDonough.

\section{Funding}

The OTESSA presentation and this short paper pre-date funding secured for this research.

\section{Ethics Statement}

The OTESSA presentation and this short paper did not involve human subjects. An ethics review was not needed.

\section{Conflict of Interest}

The author does not declare any conflict of interest.

\section{Data Availability Statement}

Data was not collected for this paper.

\section{References}

American Institutes for Research, \& Center on Technology and Disability. (2016). Accessibility tools and resources: Getting started with accessibility. Reading Rockets. https://www.readingrockets.org/article/accessibility-tools-and-resources-getting-startedaccessibility ctd

Bradbard, D. A., \& Peters, C. (2008). Web accessibility: A tutorial for university faculty. Communications of the Association for Information Systems, 22(8), 143-164. https://doi.org/10.17705/1CAIS.02208

Bradbard, D. A., \& Peters, C. (2010). Web accessibility theory and practice: An kntroduction for university faculty. The Journal of Educators Online, 7(1), 1-46.

Brown, M. (2018, January 25). Presenting the ELI key issues for 2018. Educause Review. https://er.educause.edu/blogs/2018/1/presenting-the-eli-key-issues-for-2018

Caldwell, B., Cooper, M., Reid, L. G., \& Vanderheiden, G. (Eds.). (2010). Web content accessibility guidelines (WCAG) 2.0. W3C. https://www.w3.org/WAl/GL/WCAG20/

Chen, W., Sanderson, N. C., \& Kessel, S. (2018). Making learning materials accessible in higher education-attitudes among technology faculty members. In G. Craddock, C. 
Doran, L. McNutt, \& D. Rice (Eds.), Transforming our world through design, diversity and education (pp. 87-97). IOS Press EBooks. https://doi.org/10.3233/978-1-61499-923-2-

87

Chung, A.-M., Bond Gill, I., \& O’Byrne, I. (n.d.). Web literacy 2.0. Mozilla GitHub.

https://mozilla.github.io/content/web-lit-whitepaper/

Coughlan, T., \& Lister, K. (2018). The accessibility of administrative processes: Assessing the impacts on students in higher education. W4A '18: Proceedings of the 15th International Web for All Conference, 1-10. https://doi.org/10.1145/3192714.3192820

Dolmage, J. T. (2017). Academic ableism: Disability and higher education. University of Michigan Press.

Gay, G., Djafarova, N., \& Zefi, L. (2017). Teaching accessibility to the masses. W4A '17:

Proceedings of the 14th International Web for All Conference, 1-8. https://doi.org/10.1145/3058555.3058563

Gronseth, S. (2018). Inclusive design for online and blended courses: Conneting web content accessibility guidelines and universal design for learning. Educational Renaissance, 7(1), 14-22. https://doi.org/10.33499/edren.v7i1.114

Hobbs, R. (2017). Create to learn: Introduction to digital literacy. Wiley-Blackwell.

Kimmons, R. (2017). Open to all? Nationwide evaluation of high-priority web accessibility considerations among higher education websites. Journal of Computing in Higher Education, 29(3), 434-450. https://doi.org/10.1007/s12528-017-9151-3

Lewin, T. (2015, February 12). Harvard and M.I.T. are sued over lack of closed captions. The New York Times. https://www.nytimes.com/2015/02/13/education/harvard-and-mit-suedover-failing-to-caption-online-courses.html

Lewthwaite, S., \& Sloan, D. (2016). Exploring pedagogical culture for accessibility education in computing science. W4A '16: Proceedings of the 13th International Web for All Conference, 1-4. https://doi.org/10.1145/2899475.2899490

Lippay, L. (2016, March 30). What you should know about accessibility + SEO, part 1: An intro. Moz. https://moz.com/blog/accessibility-seo-1

Lorca, P., De Andrés, J., \& Martínez, A. B. (2018). The relationship between web content and web accessibility at universities: The influence of social and cultural factors. Social Science Computer Review, 36(3), 311-330. https://doi.org/10.1177/0894439317710435

Moreno, L., \& Martinez, P. (2013). Overlapping factors in search engine optimization and web accessibility. Online Information Review, 37(4), 564-580. https://doi.org/10.1108/OIR-042012-0063

O'Byrne, W. I. (2014). Empowering learners in the reader/writer nature of the digital informational space. Journal of Adolescent \& Adult Literacy, 58(2), 102-104. https://doi.org/10.1002/jaal.337

Rogers, P. L., Berg, G. A., Boettcher, J. V., Howard, C., Justice, L., \& Schenk, K. D. (Eds.). (2009). Encyclopedia of Distance Learning, Second Edition. IGI Global. https://doi.org/10.4018/978-1-60566-198-8

Silberman, E. (2018, March 9). Promoting accessibility in the context of 21st-century higher education. Educause Review. https://er.educause.edu/blogs/2018/3/promotingaccessibility-in-the-context-of-21st-century-higher-education.

U.S. Department of Education, \& Office of Educational Technology. (2017). Reimagining the role of technology in education: 2017 national education technology plan update. https://tech.ed.gov/files/2017/01/NETP17.pdf 
Wadors Verne, L. (2019). 2019 DIAGRAM center report. Diagram Center. http://diagramcenter.org/diagram-reports/diagram-report-2019.html

Wood, L. C., Axelrod, J., Downie, J. S., Furlough, M., Unsworth, J., \& Wedaman, D. (2017). Libraries: Take AIM! Accessible instructional materials and higher education. Tufts Digital Library. http://hdl.handle.net/10427/010667 